\title{
Morphological and functional changes in bone marrow mesenchymal stem cells in rats with heart failure
}

\author{
XIULI WANG, CHUNMEI LI and HAIBIN GONG \\ Department of Cardiology, Xuzhou Central Hospital, \\ Xuzhou Cardiovascular Disease Institute, Xuzhou, Jiangsu 221009, P.R. China
}

Received June 6, 2016; Accepted February 1, 2017

DOI: $10.3892 /$ etm.2017.4341

\begin{abstract}
The changes in bone marrow-derived mesenchymal stem cells (BMSCs), in terms of cell morphology and protein expression in rats with heart failure, were studied. Pressure overload chronic heart failure rat model was induced with partial constriction of the abdominal aorta. BMSCs from the model and the sham operation groups were isolated and cultured (cell density, $10^{8}$ cells/l), and supernatant was collected after $72 \mathrm{~h}$. Enzyme-linked immunosorbent assay was used to measure HGF, IGF-1, PDGF, SCF, FGF and VEGF levels in the supernatant. Results showed that in the model group, the minimum cell diameter, the average cell area and the protein expression in single BMSCs were significantly less than those in the sham operation group. In the model group, SCF and PDGF levels were significantly lower than those in the sham operation group. VEGF concentration in the model group was significantly higher than that in the sham operation group. Compared with normal rats, the morphology of BMSCs in rats with heart failure changed considerably, the protein expression of a single cell and the ability to secrete cytokines decreased in a meaningful way.
\end{abstract}

\section{Introduction}

Heart failure is the final stage in different types of cardiovascular diseases (1), and chronic pressure overload is known to be an important cause of heart failure (2). Cellular cardiomyoplasty is a new way to improve the impaired cardiac function. It employs stem cell therapy to regenerate myocardium. Characterized by their potential for proliferation, differentiation and capacity for self-renewal, stem cells are ideally suited for use in regenerative medicine $(3,4)$. With the development of

Correspondence to: Dr Haibin Gong, Department of Cardiology, Xuzhou Central Hospital, Xuzhou Cardiovascular Disease Institute, 199 South Jiefang Road, Xuzhou, Jiangsu 221009, P.R. China E-mail: gong_haibin1@163.com

Key words: abdominal aorta constriction, heart failure, bone marrow mesenchymal stem cells stem cell technology, it is now possible to increase the number of myocardial cells with intact contractile function by cell transplantation.

The use of stem cells for regeneration purposes has been broadly studied, and bone marrow-derived mesenchymal stem cells (BMSCs) remain the most extensively investigated cells. Several advantages have been reported, however, the most dominant advantages associated with the use of BMSCs are the following: i) They have high differentiation potential; ii) they are easy to collect; iii) there is no risk of rejection after autologous transplantation; and iv) there is no ethical controversy. BMSCs are now considered as one of the hot spots in the field of transplantation research (3-13), however, there are still some questions about BMSCs that need to be answered. We do not yet know whether BMSCs in patients with heart failure have the same form and function as those in the healthy people, or whether BMSCs can play a constructive role in healthy individuals.

In the present study, the pressure overload chronic heart failure rat model was induced with partial constriction of the abdominal aorta (3). BMSCs from normal rats and heart failure rats were isolated, and all changes in cell morphology, protein expression and the ability to secrete cytokines were studied. Through this study, we provided a theoretical basis for clinical application of BMSCs.

\section{Materials and methods}

\section{Materials}

Experimental animals and cell lines. Sprague-Dawley male rats (body weight range, 200-220 g) were obtained from the Experimental Animal Center of the Chinese Academy of Sciences in Shanghai, China.

Main reagents. Fetal bovine serum (FCS) was purchased from HyClone (Logan, UT, USA), L-glutamine from Sigma-Aldrich (St. Louis, MO, USA), DMEM/F12 culture media from Gibco (Grand Island, NY, USA). Mouse monoclonal CD29 antibody (dilution, 1:200; cat. no. 368511) and mouse monoclonal CD45 antibody (dilution, 1:200; cat. no. 102216) were from BioLegend, Inc. (San Diego, CA, USA). Mouse monoclonal CD44 antibody (dilution, 1:200; cat. no. MCA643FA) was from Serotec (Oxford, UK), enzyme-linked immunosorbent assay (ELISA) kit and AEC color reagent kit from Wuhan Boster Biological Technology, 
Table I. Comparison of the hemodynamics indexes between the sham group and the model group (mean \pm SD).

\begin{tabular}{lccccc}
\hline Group & $\mathrm{n}$ & LVSP $(\mathrm{mmHg})$ & LVEDP $(\mathrm{mmHg})$ & $+\mathrm{dp} / \mathrm{dt}(\mathrm{mmHg} / \mathrm{sec})$ & $-\mathrm{dp} / \mathrm{dt}(\mathrm{mmHg} / \mathrm{sec})$ \\
\hline Sham & 20 & $121.22 \pm 11.78$ & $1.47 \pm 1.04$ & $4016.29 \pm 513.72$ & $3828.81 \pm 642.37$ \\
Model & 30 & $108.94 \pm 10.36$ & $13.30 \pm 6.53^{\mathrm{a}}$ & $2541.10 \pm 378.36^{\mathrm{b}}$ & $2475.80 \pm 327.21^{\mathrm{b}}$ \\
\hline
\end{tabular}

aP $<0.05$, ${ }^{\mathrm{P}}<0.01$ vs. Sham group.
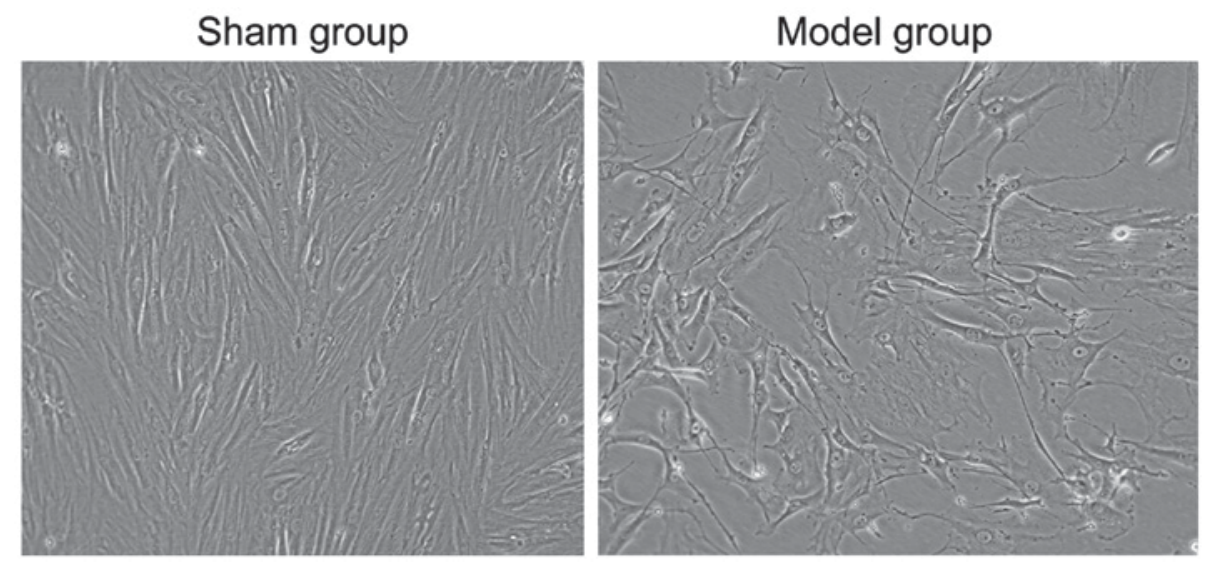

Figure 1. Sixth generation of BMSC cell culture: BMSCs in the Sham operation group rats became adherent in spindle shaped with fibroblastic morphology; BMSC morphology in the model group became irregular. BMSCs, bone marrow-derived mesenchymal stem cells.

Ltd. (Wuhan, China). ELISA kits for HGF, IGF-1, PDGF, SCF, FGF and VEGF were purchased from the US UCL Company.

Instruments. We used $\mathrm{CO}_{2}$ cell incubator (Thermo Fisher Scientific, Waltham, MA, USA), Micro-camera system (version 2.0; Olympus, Tokyo, Japan), and enzyme standard instrument (Tecan Group Ltd., Männedorf, Switzerland).

\section{Methods}

Preparation of the animal model. Rat model of pressure overload chronic heart failure was induced with partial constriction of abdominal aorta, using the protocol reported by Wang et al (13). Rats were routinely fed after operation, and hemodynamic monitoring was conducted 12 weeks after the operation.

Hemodynamic monitoring. We used the protocol reported by Wang et al for hemodynamic monitoring (13). After the operation, rats were routinely fed and hemodynamic monitoring was performed 12 weeks later. After hemodynamic monitoring, BMSCs were rapidly isolated.

Isolation and culture of BMSCs. Isolated BMSCs in the model group and sham operation group were cultured following protocols provided by Gong et al and Wang et al $(3,13)$.

BMSC surface markers detected by immunocytochemistry. The expression of BMSC surface markers, CD29 and CD44, and the hematopoietic stem cell surface marker CD45 were evaluated using immunocytochemistry. PBS was used in the control group. For immunocytochemistry we used the protocol reported by Gong et al and Wang et al $(3,13,14)$.

Collection of BMSC culture supernatant. The sixth generation of BMSCs (cell density, $10^{8}$ cells/l) was transferred to $60 \mathrm{~mm}$ cell culture flasks. Supernatant was collected after $72 \mathrm{~h}$ and stored at $-80^{\circ} \mathrm{C}$.
Table II. Comparison of BMSC forms in heart failure rats and normal rats.

\begin{tabular}{lcccc}
\hline Groups & $\mathrm{n}$ & $\begin{array}{c}\text { Maximum } \\
\text { diameter of } \\
\text { cells, } 1 / \mu \mathrm{m}\end{array}$ & $\begin{array}{c}\text { Minimum } \\
\text { diameter of } \\
\text { cells, } 1 / \mu \mathrm{m}\end{array}$ & $\begin{array}{c}\text { Average area of } \\
\text { cells, } \mathrm{r} / \mu \mathrm{m}^{2}\end{array}$ \\
\hline Sham & 20 & $109.98 \pm 26.07$ & $55.85 \pm 19.33$ & $4847.70 \pm 611.46$ \\
Model & 30 & $117.74 \pm 59.79$ & $26.21 \pm 12.93^{\mathrm{a}}$ & $2803.35 \pm 395.48^{\mathrm{a}}$
\end{tabular}

${ }^{\mathrm{a}}<0.01$ vs. Sham group. BMSCs, bone marrow-derived mesenchymal stem cells.

$H G F, I G F-1, P D G F, S C F, F G F$, and VEGF levels. ELISA was used to measure various cytokines using the instructions provided by the kit manufacturer.

Statistical analysis. Image Pro-Plus (IPP) 6.0 image analysis system was used to measure the maximum and minimum cell diameters, the average single cell area and the average gray value of a single cell. SPSS 12.0 (IBM, Armonk, NY, USA) was used for statistical analysis. The data are presented by mean \pm standard deviation. Comparison between groups was conducted using t-test. One-way ANOVA was used in for comparison among groups. $\mathrm{P}<0.05$ was set as the statistically significant difference.

\section{Results}

Hemodynamic changes. LVDEP in the model group was significantly higher than the sham operation group. Compared with the control group the $\pm \mathrm{dp} / \mathrm{dt}_{\max }$ decreased significantly in 


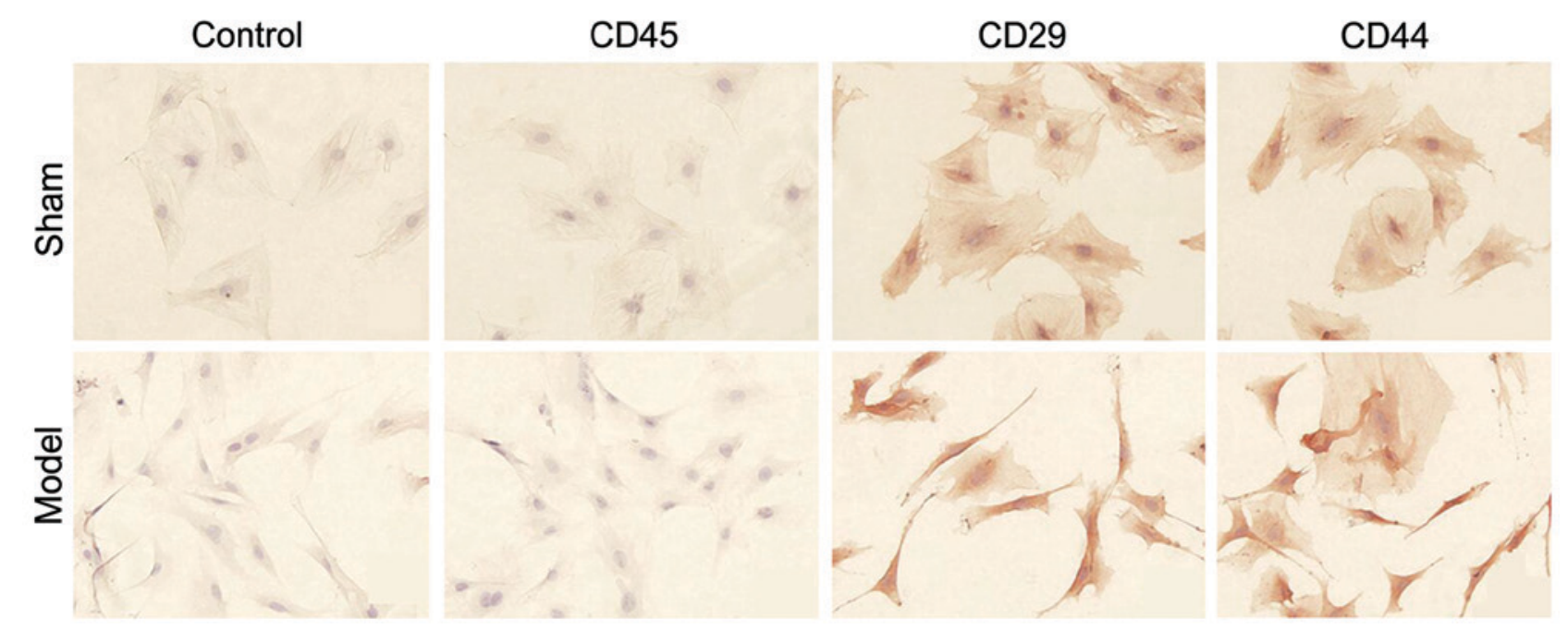

Figure 2. The identification of BMSCs by immunocytochemical staining of CD45, CD29 and CD44 in two groups (magnificaton, x400). BMSCs, bone marrow-derived mesenchymal stem cells.

Table III. Comparison of BMSCs protein expression in heart failure rats and normal rats.

\begin{tabular}{|c|c|c|c|c|}
\hline Group & $\mathrm{n}$ & Grey value & $\begin{array}{l}\text { Average area } \\
\text { of cells, } \mathrm{r} / \mu \mathrm{m}^{2}\end{array}$ & Grey value/area \\
\hline Sham & 20 & & & \\
\hline Control & & $216.26 \pm 1.10$ & & $0.0446 \pm 0.0018$ \\
\hline CD29 & & $203.13 \pm 7.08^{\mathrm{a}}$ & $4847.70 \pm 611.46$ & $0.0419 \pm 0.0116$ \\
\hline $\mathrm{CD} 44$ & & $196.76 \pm 5.06^{\mathrm{a}}$ & & $0.0406 \pm 0.0083$ \\
\hline Model & 30 & & & \\
\hline Control & & $215.21 \pm 3.74$ & & $0.0768 \pm 0.0095$ \\
\hline CD29 & & $185.85 \pm 10.90^{\mathrm{b}}$ & $2803.35 \pm 395.48$ & $0.0663 \pm 0.0276^{\mathrm{b}}$ \\
\hline CD44 & & $170.24 \pm 6.51^{\mathrm{b}}$ & & $0.0607 \pm 0.0165^{\mathrm{b}}$ \\
\hline
\end{tabular}

${ }^{a} \mathrm{P}<0.01$ vs. control group, ${ }^{\mathrm{b}} \mathrm{P}<0.01$ vs. Sham group. BMSCs, bone marrow-derived mesenchymal stem cells.

the model group. All differences were statistically significant $(\mathrm{P}<0.05)$ (Table I).

Separation and culture of BMSCs. Culture media were changed after seven days, and at this time BMSCs in the primary culture of sham operation group were in clonal distribution with various morphologies. One week later, cells reached fusion stage and when they reached P6, cell confluence was in swirling or parallel growth. Cells in the model group needed 2 weeks to fuse and reach P6, these cells were irregular in shape (large, flattened, spindle form, and cells with poles extending process-like substance). When compared with the sham operation group, there was no significant changes in the BMSC maximum cell diameter in the model group, but the minimal cell diameter and the average area of single cell were reduced. Difference was statistically significant $(\mathrm{P}<0.01)$ (Fig. 1 and Table II).

BMSC identification. Cell surface antigens were detected in both groups using immunocytochemistry staining. Positive

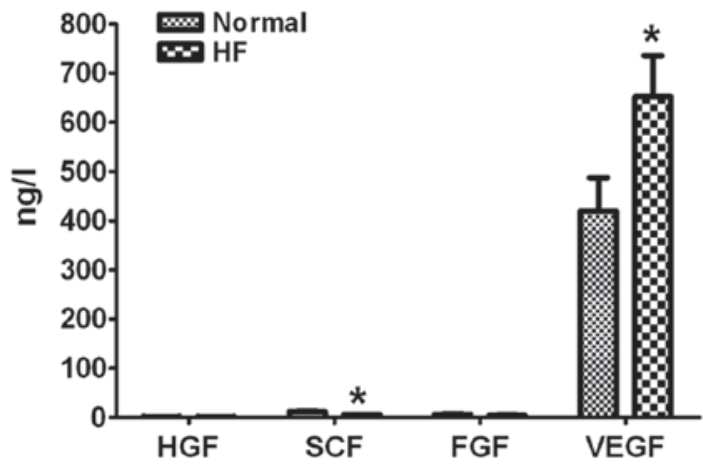

Figure 3. Comparison of VEGF, FGF, HGF and SCF secretion in BMSCs between the heart failure and normal rats. BMSCs, bone marrow-derived mesenchymal stem cells. *Compared with normal group, $\mathrm{P}<0.05$.

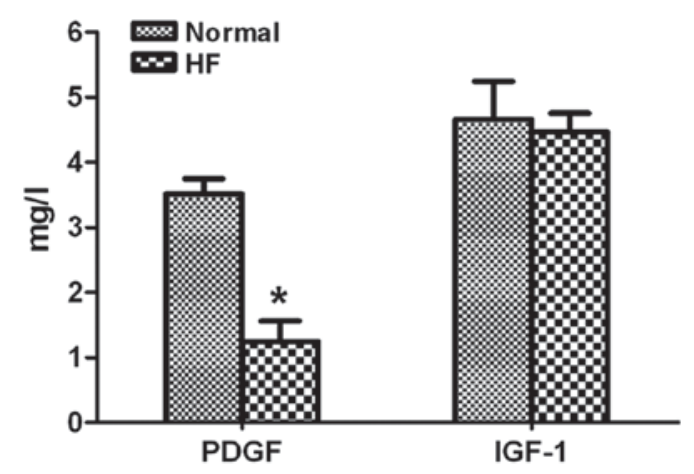

Figure 4. Comparison of PDGF and IGF-1 secretion in BMSCs between heart failure and normal rats. BMSCs, bone marrow-derived mesenchymal stem cells. *Compared with normal group, $\mathrm{P}<0.05$.

expression for CD29 and CD44 and negative for CD45 were detected. Compared with the sham operation group, the expression of CD29 and CD44 in the model group was significantly higher, and the differences were statistically significant $(\mathrm{P}<0.01)$. Nevertheless, due to the significant reduction in cell size, the amount of protein expressed by an individual cell per unit area significantly reduced (Fig. 2 and Table III). 
HGF, IGF-1, PDGF, SCF, FGF, and VEGF levels. ELISA was used to measure the level of cytokines in BMSC culture supernatant in both groups. In the model group, the average concentrations of SCF and PDGF were $6.06 \pm 1.18 \mathrm{ng} / \mathrm{l}$ and $1.25 \pm 0.32 \mathrm{mg} / 1$, respectively. These levels were significantly lower than levels detected in the sham operation group which were $12.56 \pm 1.15 \mathrm{ng} / \mathrm{l}$ and $3.52 \pm 0.23 \mathrm{mg} / 1$, respectively. Average VEGF concentration in the model group was $652.44 \pm 83.19 \mathrm{ng} / 1$, which was significantly higher than $419.97 \pm 6.785 \mathrm{ng} / \mathrm{l}$ measured in the sham operation group, and the difference had statistical significance $(\mathrm{P}<0.01)$ (Figs. 3 and 4$)$.

\section{Discussion}

Relative or absolute reduction in functional integrity of myocardial cells is the common characteristics in coronary heart disease, rheumatic heart disease and idiopathic cardiomyopathy. This condition may eventually lead to ventricular remodeling or deformation and heart failure (13-15).

Cellular cardiomyoplasty is a new method for treating patients with heart failure. Research has shown that cellular cardiomyoplasty can improve heart contractility by repairing damaged areas with new cells, and improving cardiac function $(3,16)$. Results obtained from several experimental studies and clinical trials have shown that BMSC transplantation can restore cardiac function within the myocardial damaged area $(3,8,17)$. The peak period for BMSCs in human body is during the neonatal period, and decreases with age (8). This may explain why the vast majority of patients with congestive heart failure are the elderly. In these cases, it is interesting to know whether the disease can affect the number of BMSCs or if the cells morphology and function are influenced by it.

We, in this study, have successfully prepared animal models of heart failure and discovered that significant morphological changes occurred in BMSCs in rats with chronic heart failure. The cells appeared in irregular shapes and the average area of single cell was reduced significantly. Average gray value of single BMSC in rats with heart failure was reduced significantly (smaller grey value represented stronger positive immunoreaction). Protein expression in the heart failure group increased significantly, and due to significant reduction in cell area during the heart failure, protein expression carried by unit area decreased significantly.

It has been shown that several factors such as FGF, VEGF, IGF-1, PDGF, TGF- $\beta$, Ang, EGF, G-CSF, PGF and HGF can promote cardiovascular regeneration (18). Results obtained from a prior study proved that VEGF, FGF-b, PDGF-AB/PDGFRa signaling pathway was essential for the stem cell to differentiate into cardiomyocyte-like cells (17). IGF-1 is a cytokine that promotes cardiac myocyte growth and survival, IGF-1 also promotes blood vessel regeneration in infarcted area, reduces the degree of myocardial necrosis, maintains the myocardial structure, stimulates cardiac fibroblasts proliferation, and inhibits the degradation of matrix proteins. It can effectively prevent myocardial ischemia reperfusion injury $(13,18-20)$. BMSCs have the capacity to produce and secrete several paracrine factors, which can affect BMSC migration, promote blood vessel generation and reduce the rate of cell apoptosis (21). The BMSC capacity to repair myocardial tissue depends on the secretion of nutrient factors and not on their differentiation potential (22-24). BMSCs secrete nutrient factors to improve cardiac function through a variety of complex mechanisms, such as reducing tissue damage, inhibiting fibrosis formation, promoting angiogenesis, mobilization of host tissue stem cells and reducing inflammation. It has been shown that in the course of treatment with BMSCs, VEGF is the major secreted nutritional factor (25). VEGF promotes stem cell differentiation into myocardial cells and endothelial cells $(26,27)$, and can mobilize bone marrow progenitor cells to participate in muscle formation and angiogenesis (28).

We discovered that PDGF and SCF levels decreased significantly in the heart failure group, while VEGF level surged significantly in this group. Usually, VEGF expression happens under both physiological and pathological conditions. In physiological conditions, many normal tissues express low levels of VEGF, however, VEGF expression is generally more elevated in myocardium, prostate and adrenal cortex. In pathological conditions, VEGF transcription and translation in tumor cells are highly upregulated. Elevated expression of VEGF has been also reported in non-neoplastic lesions, such as wound healing, ischemic myocardial cells, psoriasis, chlamydia, diabetic retinopathy and rheumatoid arthritis (29). In most cases of heart failure, patients suffer from myocardial remodeling and myocardial fibrosis, myocardial remodeling reduces the number of capillaries in the unit weight of myocardium and increases oxygen diffusion, so the myocardium is relatively hypoxia. Thus, during heart failure, due to myocardial hypoxic, VEGF is over-expressed, which corresponds well with our results showing that BMSCs intensify the VEGF secretion during heart failure.

In conclusion, we showed that heart failure had a profound impact on: i) BMSC morphology; ii) protein expression; and iii) the ability to secrete cytokines. Although BMSC transplantation has broad application prospects for the treatment of heart failure, it is yet unknown whether the BMSCs can help those patients in poor condition.

\section{Acknowledgements}

This study was supported by the National Nature Science Foundation of China (grant no. 30572073); the Life Health Science and Technology Projects funded by the Jiangsu Special Funds (grant no. BL2012019); the Jiangsu Key Talents of Medical Science (grant no. RC2007024); the Xuzhou Science and Technology Development Project (grant no. XF10C029); and the Xuzhou Science and Technology Development Project (grant no. XM12B062).

\section{References}

1. Braunwald E and Bristow MR: Congestive heart failure: fifty years of progress. Circulation 102 (Suppl 4): IV14-IV23, 2000.

2. Hodges P: Heart failure: epidemiologic update. Crit Care Nurs Q 32: 24-32, 2009.

3. Bernstein HS and Srivastava D: Stem cell therapy for cardiac disease. Pediatr Res 71: 491-499, 2012.

4. Uitterdijk A, Groenendijk BC and van Der Giessen WJ: Stem cell therapy for chronic heart failure. Hellenic J Cardiol 50: 127-132, 2009.

5. Kato T, Heike T, Okawa K, Haruyama M, Shiraishi K, Yoshimoto $M$, Nagato M, Shibata M, Kumada T, Yamanaka Y, et al: A neurosphere-derived factor, cystatin C, supports differentiation of ES cells into neural stem cells. Proc Natl Acad Sci USA 103: 6019-6024, 2006. 
6. Smits AM, van Vliet P, Hassink RJ, Goumans MJ and Doevendans PA: The role of stem cells in cardiac regeneration. J Cell Mol Med 9: 25-36, 2005.

7. Bobis S, Jarocha D and Majka M: Mesenchymal stem cells: Characteristics and clinical applications. Folia Histochem Cytobiol 44: 215-230, 2006.

8. Li X, Yu X, Lin Q, Deng C, Shan Z, Yang M and Lin S: Bone marrow mesenchymal stem cells differentiate into functional cardiac phenotypes by cardiac microenvironment. J Mol Cell Cardiol 42: 295-303, 2007.

9. Kosmala W, Plaksej R, Strotmann JM, Weigel C, Herrmann S, Niemann M, Mende H, Störk S, Angermann CE Wagner JA, et al: Progression of left ventricular functional abnormalities in hypertensive patients with heart failure: an ultrasonic two-dimensional speckle tracking study. J Am Soc Echocardiogr 21: 1309-1317, 2008.

10. Hauptman PJ, Rich MW, Heidenreich PA, Chin J, Cummings N Dunlap ME, Edwards ML, Gregory D, O'connor CM, Pezzella SM, et al; Heart Failure Society of America: The heart failure clinic: a consensus statement of the Heart Failure Society of America. J Card Fail 14: 801-815, 2008.

11. Leacche M, Balaguer JM and Byrne JG: Role of cardiac surgery in the post-myocardial infarction patient with heart failure. Curr Heart Fail Rep 5: 204-210, 2008.

12. Wen Z, Zheng S, Zhou C, Wang J and Wang T: Repair mechanisms of bone marrow mesenchymal stem cells in myocardial infarction. J Cell Mol Med 15: 1032-1043, 2011.

13. Mathiasen AB, Qayyum AA, Jørgensen E, Helqvist S, FischerNielsen A, Kofoed KF, Haack-Sørensen M, Ekblond A and Kastrup J: Bone marrow-derived mesenchymal stromal cell treatment in patients with severe ischaemic heart failure: a randomized placebo-controlled trial (MSC-HF trial). Eur Heart J 36: 1744-1753, 2015.

14. Cohn JN: Structural basis for heart failure. Ventricular remodeling and its pharmacological inhibition. Circulation 91: 2504-2507, 1995.

15. Konstam MA, Kramer DG, Patel AR, Maron MS and Udelson JE: Left ventricular remodeling in heart failure: current concepts in clinical significance and assessment. JACC Cardiovasc Imaging 4: 98-108, 2011.

16. Miyagawa S, Sawa Y, Taketani S, Kawaguchi N, Nakamura T, Matsuura $\mathrm{N}$ and Matsuda $\mathrm{H}$ : Myocardial regeneration therapy for heart failure: hepatocyte growth factor enhances the effect of cellular cardiomyoplasty. J Cardiol 41: 36-38, 2003 (In Japanese).

17. Perin EC, Dohmann HF, Borojevic R, Silva SA, Sousa AL, Mesquita CT, Rossi MI, Carvalho AC, Dutra HS, Dohmann HJ, et al: Transendocardial, autologous bone marrow cell transplantation for severe, chronic ischemic heart failure. Circulation 107: 2294-2302, 2003.
18. Nakamura T, Mizuno S, Matsumoto K, Sawa Y, Matsuda H and Nakamura T: Myocardial protection from ischemia/reperfusion injury by endogenous and exogenous HGF. J Clin Invest 106: $1511-1519,2000$

19. Arcopinto M, Bobbio E, Bossone E, Perrone-Filardi P, Napoli R, Sacca L and Cittadini A: The GH/IGF-1 axis in chronic heart failure. Endocr Metab Immune Disord Drug Targets 13: 76-91, 2013.

20. Samani AA, Yakar S, LeRoith D and Brodt P: The role of the IGF system in cancer growth and metastasis: overview and recent insights. Endocr Rev 28: 20-47, 2007.

21. Boomsma RA and Geenen DL: Mesenchymal stem cells secrete multiple cytokines that promote angiogenesis and have contrasting effects on chemotaxis and apoptosis. PLoS One 7: e35685, 2012

22. Gnecchi M, Zhang Z, Ni A and Dzau VJ: Paracrine mechanisms in adult stem cell signaling and therapy. Circ Res 103 1204-1219, 2008.

23. Kinnaird T, Stabile E, Burnett MS, Lee CW, Barr S, Fuchs S and Epstein SE: Marrow-derived stromal cells express genes encoding a broad spectrum of arteriogenic cytokines and promote in vitro and in vivo arteriogenesis through paracrine mechanisms. Circ Res 94: 678-685, 2004.

24. Lee RH, Pulin AA, Seo MJ, Kota DJ, Ylostalo J, Larson BL, Semprun-Prieto L, Delafontaine P and Prockop DJ: Intravenous hMSCs improve myocardial infarction in mice because cells embolized in lung are activated to secrete the anti-inflammatory protein TSG-6. Cell Stem Cell 5: 54-63, 2009.

25. Zisa D, Shabbir A, Suzuki G and Lee T: Vascular endothelial growth factor (VEGF) as a key therapeutic trophic factor in bone marrow mesenchymal stem cell-mediated cardiac repair. Biochem Biophys Res Commun 390: 834-838, 2009.

26. Song YH, Gehmert S, Sadat S, Pinkernell K, Bai X, Matthias N and Alt E: VEGF is critical for spontaneous differentiation of stem cells into cardiomyocytes. Biochem Biophys Res Commun 354: 999-1003, 2007.

27. Oswald J, Boxberger S, Jørgensen B, Feldmann S, Ehninger G, Bornhäuser $M$ and Werner $C$ : Mesenchymal stem cells can be differentiated into endothelial cells in vitro. Stem Cells 22: 377-384, 2004.

28. Asahara T, Takahashi T, Masuda H, Kalka C, Chen D, Iwaguro H, Inai Y, Silver M and Isner JM: VEGF contributes to postnatal neovascularization by mobilizing bone marrow-derived endothelial progenitor cells. EMBO J 18: 3964-3972, 1999.

29. Maeda K, Chung YS, Ogawa Y, Takatsuka S, Kang SM, Ogawa M, Sawada T and Sowa M: Prognostic value of vascular endothelial growth factor expression in gastric carcinoma. Cancer 77: 858-863, 1996. 